\title{
Inbreeding depression on beef cattle traits: Estimates, linearity of effects and heterogeneity among sire-families
}

\author{
Nuno CARolino ${ }^{1}$, Luis T. Gama ${ }^{1,2 *}$ \\ ${ }^{1}$ Estação Zootécnica Nacional - INRB, 2005-048 Vale de Santarém, Portugal \\ ${ }^{2}$ Faculdade de Medicina Veterinária - Universidade Técnica de Lisboa, \\ 1300-477 Lisboa, Portugal
}

(Received 10 December 2007; accepted 25 March 2008)

\begin{abstract}
Records from up to 19054 registered cows and 10297 calves in 155 herds of the Alentejana cattle breed were used to study the effects of individual $\left(\mathrm{F}_{\mathrm{i}}\right)$ and maternal $\left(\mathrm{F}_{\mathrm{m}}\right)$ inbreeding on reproductive, growth and carcass traits, as well as assessing the importance of non-linear associations between inbreeding and performance, and evaluating the differences among sire-families in the effect of $F_{i}$ and $F_{m}$ on calf weight at 7 months of age (W7M). Overall, regression coefficients of performance traits on inbreeding were small, indicating a minor but still detrimental effect of both $F_{i}$ and $F_{m}$ on most traits. The traits with the highest percentage impact of $F_{i}$ were total number of calvings through life and calf weight at 3 months of age (W3M), followed by longevity and number of calves produced up to 7 years, while the highest effect of $F_{m}$ was on W3M. Inbreeding depression on feed efficiency and carcass traits was extremely small and not significant. No evidence was found of a non-linear association between inbreeding and performance for the traits analyzed. Large differences were detected among sire-families in inbreeding depression on W7M, for both $F_{i}$ and $F_{m}$, encouraging the possibility of incorporating sire effects on inbreeding depression into selection decisions.
\end{abstract}

Alentejana / cattle / inbreeding depression / individual inbreeding / maternal inbreeding

\section{INTRODUCTION}

The Alentejana belongs to the Red Convex group of European southern breeds, which is thought to be of African origin [21], and is one of the major native breeds of cattle in Portugal. The breed numbers declined in the mid20th century, due to unplanned crossbreeding with exotic breeds, but have recovered in recent decades, and currently there are about 11000 cows registered in the herdbook [4]. Alentejana herds are traditionally raised under extensive conditions, in oak- and cork-tree forests, or integrated with grain production

*Corresponding author: genetica.ezn@mail.telepac.pt 
systems in dry lands. In a recent demographic analysis of Alentejana, Carolino and Gama [4] reported that the estimated rate of increase in inbreeding per year and generation was 0.33 and $2.15 \%$, respectively, the mean level of inbreeding for calves born in 2003 was $8.5 \%$ and 33 ancestors contributed $50 \%$ to the current genetic pool of the breed. Taken together, these results reflect the fast genetic erosion that the breed has experienced over the years, with a realized effective population size of 23 [4], which is less than half the recommended minimum number to maintain genetic diversity $[12,24]$.

The detrimental impact of inbreeding on performance traits, especially those which are fitness related, has been widely recognized and is a result of the reduction in heterozygosity as inbreeding accumulates $[9,11,20]$. The genetic basis of inbreeding depression has been explained by two main hypotheses, i.e., the overdominance hypothesis, where it is assumed that fitness is higher in heterozygotes than in any of the homozygotes, and the dominance hypothesis, where it is assumed that recessive deleterious alleles may affect fitness, such that heterozygotes have a fitness which is close to the wildtype $[18,20]$. Depending on the hypothesis assumed, the impact of selection and the evolutionary consequences would be different. In the overdominance hypothesis, selection would favor heterozygous individuals, and thus recessive alleles would be maintained. On the contrary, in the dominance hypothesis, recessive alleles would be purged by selection, unless mutation occurs continuously to maintain the genetic load of deleterious recessive alleles [18]. Under the dominance hypothesis, a slow increase in inbreeding would allow selection to act, such that the resulting inbreeding depression would be lower than if inbreeding increased at a faster rate, and this has been supported by experimental results with several laboratory species $[10,26]$.

In traits affected by maternal effects [37], it can be expected that both individual and maternal inbreeding may have a detrimental effect on performance, and both should be taken into account when evaluating the impact of inbreeding [11].

The effects of inbreeding on productive traits in beef cattle have been reviewed by Burrow [2], largely based on studies with actively inbred research populations. Even though inbreeding had a detrimental effect on most traits, the general conclusion was that its impact was minor, and inbreeding should thus be of little concern to most commercial beef producers. Nevertheless, inbreeding depression is a function of allele frequencies at the loci affecting the traits of interest and is therefore expected to differ among breeds and populations [11]. Furthermore, the level of inbreeding depression has been shown to be higher when inbreeding effects are expressed in harsh environmental conditions [18]. 
Therefore, it can be argued that breeds kept in extensive systems, often under serious climatic and feed constraints, are expected to show a more pronounced impact of inbreeding depression.

The linear association often assumed between inbreeding and performance is compatible with the dominance hypothesis, as it would correspond to the loss of heterozygosity and increased frequency of deleterious recessive homozygotes as inbreeding accumulates. Nevertheless, if epistatic effects are also involved in inbreeding depression, a non-linear decline in mean performance would result from accumulated inbreeding [6]. Evidence of a non-linear association between inbreeding and performance has been detected in several traits in dairy cattle $[8,16,22,32,33]$, but to our knowledge it has not been documented for other livestock species.

Frequently, inbreeding depression is estimated by regression of the trait of interest on inbreeding, assuming a single slope. This approach is based on the premise that the increase in homozygosity due to identity by descent is the same, regardless of the common ancestor contributing to it. Nevertheless, it can be envisaged that different ancestors contributing to inbreeding may carry a different genetic load, e.g., recessive deleterious alleles, and inbreeding depression would then differ among families [19]. Indeed, heterogeneity in inbreeding depression among founder families has been reported, for example, in mice [19], swine [27] and dairy cattle [15,25].

The specific demographic features of the Alentejana breed, especially its high level and rate of inbreeding, as well as the reduced number of influential ancestors, make it an interesting resource population to study the effects of inbreeding on beef cattle traits, assuming different genetic-statistical models. Therefore, the objectives of this work were the following: (a) to study the effect of individual and maternal inbreeding on reproductive, growth and carcass traits in the Alentejana cattle breed; (b) to assess the possible existence of a non-linear association between inbreeding and performance traits; and (c) to evaluate if there are differences among sire-families in the effect of individual and maternal inbreeding on calf weight at 7 months of age (W7M).

\section{MATERIALS AND METHODS}

\subsection{Data}

Pedigree and performance records were collected between 1944 and 2005, on 155 farms enrolled in the Alentejana Herdbook. This herdbook has been closed since 1991 and currently has about 11000 registered cows. All calves registered 
in the period 2000-2003 ( $n=28631)$ had known parents and 96.9\% had known grandparents, and the mean number of generations known and average inbreeding for those calves were $4.06 \pm 1.20$ and $8.35 \pm 9.02 \%$, respectively [4]. The on-farm performance records considered in this work included calving interval (CI), age at first calving (AFC), productive longevity (PL), number of calvings up to 7 years of age (NC7) and through life (NCT), birth weight (BW), calf weight adjusted to 3 months (W3M), 7 months (W7M) and 12 months (W12M), and mature weight (MW). The adjusted weight at 3 months for the $i$ th calf was calculated as:

$$
\mathrm{W} \mathrm{M}_{i}=\mathrm{BW}_{i}+\left[\left(\left(W_{i}-\mathrm{BW}_{i}\right) /\left(\mathrm{Age}_{i}\right)\right) \times 90\right],
$$

where $W_{i}$ corresponds to the weight obtained at the age $\left(\mathrm{Age}_{i}\right)$ closer to 90 days, within a limit of \pm 45 days. Weights adjusted for the other ages were obtained following the same principles. The MW was obtained as the average of body weights after 3.5 years of age, for animals which had at least three weights recorded.

Records were also collected between 1973 and 2003 in the performance testing center of the Alentejana breed, including information on 1203 bulls. The traits considered were average daily gain (ADG) on test, feed to gain ratio (FGR) and relative growth rate (RGR), which was calculated for the $i$ th calf as:

$$
\mathrm{RGR}_{i}=\frac{\log \left(\text { Final weight }_{i}\right)-\log \left(\text { Initial weight }_{i}\right)}{\text { Test length }} \times 100 .
$$

The RGR can be considered as an approximation of the rate of maturity applied to a short period of time and corresponds to daily gain expressed as a proportion of live weight [13].

Carcass information was collected through the certification program of "Carnalentejana, D.O.P.", and the records considered in our work included information on 7701 calves, slaughtered between 1995 and 2004 under the certification program. For the purposes of this analysis, retail meat yield (RY) as the percentage of carcass weight and the percentage of meat cuts in the extra category (EX, including tenderloin and striploin) were considered.

\subsection{Statistical analyses}

The individual coefficients of inbreeding were obtained from the relationship matrix [34] using pedigree information from all generations, which included 98019 animals. 
Each trait was analyzed with a mixed linear model, including the fixed and random effects specified in Table I, and all analyses were carried out with Multiple Trait Derivative Free REML (MTDFREML) [1]. The additive direct genetic effect was included as a random component for all traits, while for CI the permanent environmental effect of the cow was also considered, and in calf weights up to 12 months the maternal genetic effect was also incorporated in the mixed model, in addition to the permanent environmental effect of the dam. Genetic parameters previously estimated for this data set [5] were used in the different analyses and are summarized in Table I.

Inbreeding depression was first estimated by including in the fixed part of the model a covariate corresponding to the coefficient of inbreeding of the individual $\left(\mathrm{F}_{\mathrm{i}}\right)$. For those traits where maternal genetic effects were considered, the model included additionally a covariate corresponding to the coefficient of inbreeding of the dam $\left(\mathrm{F}_{\mathrm{m}}\right)$.

A second univariate analysis was carried out for all traits, to assess the possibility of a non-linear effect of inbreeding of the calf or dam, by including in the mixed model the corresponding linear and quadratic effects.

An additional statistical analysis was also implemented, to evaluate possible differences among sire-families in the effect of individual and maternal inbreeding on W7M. For this analysis, sires which had the major contribution as common ancestors to the parents of calves with W7M information were identified. The sires had at least 30 inbred offspring with records. A total of 19 bulls were identified, with an average of 242 offspring/bull. The same criterion was used to select sires which were common ancestors of inbred dams of calves with W7M information, and 17 bulls were identified. For this analysis, the mixed model was similar to the one used before, but an individual linear regression coefficient was estimated for each one of the most influential sires, either as an ancestor of the calves or of the dams. As a first approximation, it was assumed that the computed inbreeding coefficient of a given calf or dam was only a result of the contribution of the major common ancestor, and these inbreeding coefficients were used as covariates in the fixed part of the model, as suggested by Miglior et al. [25]. Calves which were inbred, but where the leading common ancestor was not one of the major sires, were considered to be inbred due to the contribution of a phantom ancestor, and additional regression coefficients were included for this phantom bull, both as ancestor of the calves and dams. Overall, 20 regression coefficients were included in the model to represent ancestors of calves (19 major bulls and one phantom ancestor), with the coefficient of inbreeding of a given calf being represented as a covariate in the vector corresponding to its major ancestor, while the covariate was set to zero in vectors corresponding to other bulls. 
Table I. Fixed and random effects and genetic parameters considered in the Animal Model for each trait analyzed.

\begin{tabular}{|c|c|c|c|c|c|c|c|c|c|c|c|c|c|}
\hline \multirow[t]{2}{*}{ Trait $^{\mathrm{a}}$} & \multicolumn{9}{|c|}{ Fixed effects ${ }^{b}$} & \multicolumn{4}{|c|}{ Random effects ${ }^{c}$} \\
\hline & HY & Month & Sex & $\begin{array}{l}\text { Age at } \\
\text { calving }\end{array}$ & $\mathrm{AFC}$ & $\begin{array}{c}\text { Start } \\
\text { weight }\end{array}$ & $\begin{array}{c}\text { Carcass } \\
\text { weight }\end{array}$ & $\mathrm{F}_{\mathrm{i}}(\%)$ & $\mathrm{F}_{\mathrm{m}}(\%)$ & $h_{\mathrm{a}}^{2}$ & $h_{\mathrm{m}}^{2}$ & $c^{2}$ & $r_{\mathrm{am}}$ \\
\hline CI (d) & $\mathrm{X}$ & $\mathrm{X}$ & $X$ & $\mathrm{X}$ & & & & $\mathrm{X}$ & & 0.03 & & 0.05 & \\
\hline $\mathrm{AFC}(\mathrm{m})$ & $X$ & $X$ & & & & & & $X$ & & 0.06 & & & \\
\hline PL (m) & $X$ & $X$ & & & $X$ & & & $X$ & & 0.06 & & & \\
\hline $\mathrm{NC7}(n)$ & $X$ & $X$ & & & $X$ & & & $X$ & & 0.04 & & & \\
\hline $\operatorname{NCT}(n)$ & $X$ & $X$ & & & $X$ & & & $X$ & & 0.05 & & & \\
\hline BW (kg) & $X$ & $X$ & $X$ & X & & & & $X$ & X & 0.56 & 0.17 & 0.02 & -0.79 \\
\hline W3M (kg) & $\mathrm{X}$ & $X$ & $\mathrm{X}$ & $\mathrm{X}$ & & & & $\mathrm{X}$ & $\mathrm{X}$ & 0.32 & 0.05 & 0.11 & -0.68 \\
\hline W7M (kg) & $X$ & $X$ & $X$ & $X$ & & & & $X$ & $X$ & 0.50 & 0.21 & 0.04 & -0.81 \\
\hline W12M (kg) & $X$ & $X$ & $X$ & $X$ & & & & $X$ & $X$ & 0.21 & 0.18 & 0.00 & -0.19 \\
\hline MW (kg) & $X$ & $X$ & $X$ & $\mathrm{X}$ & & & & $X$ & & 0.24 & & & \\
\hline $\operatorname{ADG}\left(g \cdot d^{-1}\right)$ & $X$ & $X$ & & & & $X$ & & $X$ & & 0.15 & & & \\
\hline FGR $\left(\mathrm{kg} \cdot \mathrm{kg}^{-1}\right)$ & $X$ & $X$ & & & & $\mathrm{X}$ & & $X$ & & 0.13 & & & \\
\hline $\operatorname{RGR}\left(\% \cdot \mathrm{d}^{-1}\right)$ & $\mathrm{X}$ & $\mathrm{X}$ & & & & $\mathrm{X}$ & & $\mathrm{X}$ & & 0.17 & & & \\
\hline $\mathrm{EX}(\%)$ & $X$ & $\mathrm{X}$ & & & & & $X$ & $X$ & & 0.20 & & & \\
\hline RY (\%) & $X$ & $X$ & & & & & $X$ & $X$ & & 0.19 & & & \\
\hline
\end{tabular}

${ }^{\mathrm{a}} \mathrm{CI}$ - calving interval; AFC - age at first calving; PL - productive longevity; NC7 - number of calvings up to 7 years of age; NCT - lifetime number of calvings; BW - birth weight; W3M - weight at 3 months; W7M - weight at 7 months; W12M - weight at 12 months; MW - mature weight; ADG average daily gain; FGR - feed to gain ratio; RGR - relative growth rate; EX - percentage of extra meat cuts; RY - retail meat yield.

${ }^{b} \mathrm{HY}$ - herd-year; AFC - age at first calving; $\mathrm{F}_{\mathrm{i}}$ - individual coefficient of inbreeding; $\mathrm{F}_{\mathrm{m}}$ - maternal coefficient of inbreeding.

${ }^{\mathrm{c}} h_{\mathrm{a}}^{2}$ - heritability of direct genetic effects; $h_{\mathrm{m}}^{2}$ - heritability of maternal genetic effects; $c^{2}$ - proportion of phenotypic variance due to permanent environmental effects; $r_{\mathrm{am}}$ - correlation between direct and maternal genetic effects. 
A similar principle was used for dam's inbreeding effect, and 18 regression coefficients were estimated for ancestors of dams (17 major bulls and one phantom ancestor). For this analysis, of the 7865 calves with W7M information, 6342 were inbred, of which 5206 were offspring of the major bulls, and 1136 were assigned to the phantom ancestor. In this analysis, breeding values for the direct and maternal genetic components of W7M were also predicted with MTDFREML [1], and the correlations between inbreeding depression due to a given sire-ancestor and its direct and maternal breeding values were estimated.

\section{RESULTS}

The number of records per trait, and the corresponding means, are presented in Table II, as well as the average inbreeding for calves and dams included in the analyses. Given the structure of the data set, the number of records was the highest for reproductive traits and the lowest for traits measured in central performance testing. The inbreeding coefficients of animals with records used for the different analyses also depended on the trait considered, such that the mean inbreeding of calves ranged between 3.01 and $7.93 \%$, while for dams the range was between 3.52 and $4.88 \%$. As an example, the distribution of inbreeding coefficients of calves with W7M information is in Figure 1, where the mean inbreeding was $6.75 \pm 6.71 \%$ and the median was $4.60 \%$.

The estimated linear regression coefficients of the different traits on inbreeding of the calf and dam, obtained from mixed model analyses, are presented in Table III. The vast majority of the regression coefficients were highly significant $(P<0.01)$, with the exception of the direct influence on $\mathrm{CI}$ and the maternal influence on $\mathrm{W} 3 \mathrm{M}$, which were significant $(P<0.05)$. There was no significant effect of $F_{i}$ on FGR, RGR, EX and RY and of $F_{m}$ on W12M. Furthermore, the effect of inbreeding was always unfavorable, i.e., the regression coefficients were positive for CI, AFC and FGR (where an increase is undesirable), and negative for all the other traits.

Overall, the regression coefficients were small, indicating a minor but still unfavorable effect of both individual and maternal inbreeding on the traits analyzed. All traits associated with reproductive efficiency and longevity showed a significant effect of inbreeding of the cow, with a decline of nearly 0.02 calves produced through life and a reduction in longevity of about 0.2 months per $1 \%$ increase in $F_{i}$. The influence of $F_{m}$ was similar for calf weights between 3 and 12 months of age, but much smaller for BW. On the contrary, the effects of $F_{i}$ were more pronounced for weight at 3 and 12 months than at 7 months and were minor for BW. The MW decreased with $\mathrm{F}_{\mathrm{i}}$ (nearly $1 \mathrm{~kg} / 1 \% \mathrm{~F}_{\mathrm{i}}$ ), but the 
Table II. Number of records, global means $(\bar{X})$ and average coefficients of individual $\left(\overline{\mathrm{F}}_{\mathrm{i}}\right)$ and maternal $\left(\overline{\mathrm{F}}_{\mathrm{m}}\right)$ inbreeding for the traits analyzed.

\begin{tabular}{|c|c|c|c|c|}
\hline Trait $^{\mathrm{a}}$ & $n$ & $\bar{X}$ & $\bar{F}_{i}(\%)$ & $\overline{\mathrm{F}}_{\mathrm{m}}(\%)$ \\
\hline CI (d) & 42224 & 442.74 & 6.05 & - \\
\hline $\mathrm{AFC}(\mathrm{m})$ & 19054 & 37.15 & 5.55 & - \\
\hline PL (m) & 14920 & 112.57 & 3.31 & - \\
\hline $\mathrm{NC7}(n)$ & 17395 & 2.53 & 3.18 & - \\
\hline $\operatorname{NCT}(n)$ & 7060 & 4.71 & 3.32 & - \\
\hline BW (kg) & 10297 & 33.76 & 5.88 & 4.34 \\
\hline W3M (kg) & 2525 & 108.77 & 6.07 & 3.52 \\
\hline W7M (kg) & 7865 & 213.10 & 6.75 & 4.88 \\
\hline W12M (kg) & 2661 & 323.68 & 6.69 & 4.16 \\
\hline MW (kg) & 2541 & 677.28 & 4.46 & - \\
\hline $\operatorname{ADG}\left(g \cdot d^{-1}\right)$ & 1203 & 1253.5 & 3.01 & - \\
\hline FGR $\left(\mathrm{kg} \cdot \mathrm{kg}^{-1}\right)$ & 1203 & 6.11 & 3.01 & - \\
\hline $\operatorname{RGR}\left(\% \cdot \mathrm{d}^{-1}\right)$ & 1203 & 0.34 & 3.01 & - \\
\hline EX (\%) & 7701 & 10.06 & 7.93 & - \\
\hline RY (\%) & 7701 & 70.13 & 7.93 & - \\
\hline
\end{tabular}

${ }^{\mathrm{a}}$ See Table I for definition of trait abbreviations.

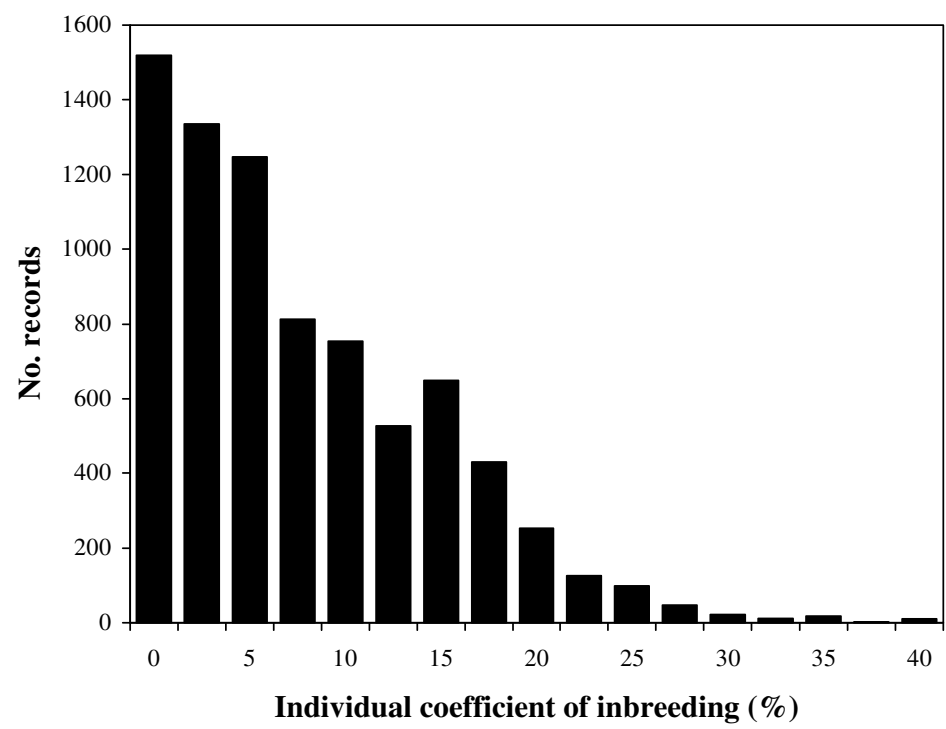

Figure 1. Distribution of observations by level of inbreeding, for calves considered in the analysis of weight at 7 months of age (W7M). 
Table III. Estimated linear regression coefficients \pm SE of performance traits on individual $\left(F_{i}\right)$ and maternal $\left(F_{m}\right)$ inbreeding, and their values expressed as a percentage of the trait mean and of phenotypic standard deviation $\left(\sigma_{\mathrm{P}}\right)$.

\begin{tabular}{|c|c|c|c|c|c|c|}
\hline \multirow[t]{2}{*}{ Trait $^{b}$} & \multicolumn{2}{|c|}{ Regression coefficients $^{\mathrm{a}}$} & \multicolumn{2}{|c|}{$\%$ of trait mean } & \multicolumn{2}{|c|}{$\%$ of trait $\sigma_{\mathrm{P}}$} \\
\hline & $\mathrm{F}_{\mathrm{i}}(\%)$ & $\mathrm{F}_{\mathrm{m}}(\%)$ & $\mathrm{F}_{\mathrm{i}}(\%)$ & $\mathrm{F}_{\mathrm{m}}(\%)$ & $\mathrm{F}_{\mathrm{i}}(\%)$ & $\mathrm{F}_{\mathrm{m}}(\%)$ \\
\hline CI (d) & $+0.263 \pm 0.119^{*}$ & - & +0.06 & - & +0.19 & \\
\hline $\mathrm{AFC}(\mathrm{m})$ & $+0.022 \pm 0.007^{* *}$ & - & +0.06 & - & +0.28 & \\
\hline PL (m) & $-0.204 \pm 0.065^{* *}$ & - & -0.18 & - & -0.43 & \\
\hline NC7 $(n)$ & $-0.004 \pm 0.001^{* *}$ & - & -0.16 & - & -0.32 & \\
\hline $\operatorname{NCT}(n)$ & $-0.019 \pm 0.007^{* *}$ & - & -0.40 & - & -0.59 & \\
\hline BW (kg) & $-0.027 \pm 0.007^{* *}$ & $-0.020 \pm 0.007^{* *}$ & -0.08 & -0.06 & -0.54 & -0.40 \\
\hline W3M (kg) & $-0.327 \pm 0.079^{* *}$ & $-0.205 \pm 0.091^{*}$ & -0.30 & -0.19 & -1.56 & -0.98 \\
\hline W7M (kg) & $-0.189 \pm 0.074^{* *}$ & $-0.214 \pm 0.073^{* *}$ & -0.09 & -0.10 & -0.45 & -0.51 \\
\hline W12M (kg) & $-0.322 \pm 0.099^{* *}$ & $-0.237 \pm 0.223$ & -0.10 & -0.07 & -0.36 & -0.27 \\
\hline MW (kg) & $-0.962 \pm 0.225^{* *}$ & - & -0.14 & - & -1.10 & \\
\hline $\operatorname{ADG}\left(\mathrm{g} \cdot \mathrm{d}^{-1}\right)$ & $-0.679 \pm 0.098^{* *}$ & - & -0.05 & - & -0.34 & \\
\hline FGR $\left(\mathrm{kg} \cdot \mathrm{kg}^{-1}\right)$ & $+0.004 \pm 0.005$ & - & +0.06 & - & +0.26 & \\
\hline $\operatorname{RGR}\left(\% \cdot \mathrm{d}^{-1}\right)$ & $-0.000064 \pm 0.000209$ & - & -0.02 & - & -0.07 & \\
\hline $\mathrm{EX}(\%)$ & $-0.000057 \pm 0.000156$ & - & -0.01 & - & -0.01 & \\
\hline RY (\%) & $-0.0063 \pm 0.0043$ & - & -0.01 & - & -0.23 & \\
\hline
\end{tabular}

${ }^{\mathrm{a}}$ Level of significance of regression coefficients: ${ }^{*} P<0.05 ;{ }^{* *} P<0.01$.

${ }^{\mathrm{b}}$ See Table I for definition of trait abbreviations. 
Table IV. Linear $\left(b_{1}\right)$ and quadratic $\left(b_{2}\right)$ regression coefficients \pm SE of performance traits on individual $\left({ }_{\mathrm{i}}\right)$ and maternal $(\mathrm{m})$ inbreeding ${ }^{\mathrm{a}}$.

\begin{tabular}{|c|c|c|c|c|}
\hline \multirow[t]{2}{*}{ Trait $^{b}$} & \multicolumn{2}{|c|}{ Individual inbreeding (\%) } & \multicolumn{2}{|c|}{ Maternal inbreeding (\%) } \\
\hline & $b_{1 \mathrm{i}}$ & $b_{2 \mathrm{i}}$ & $b_{1 \mathrm{~m}}$ & $b_{2 \mathrm{~m}}$ \\
\hline CI (d) & $+0.139 \pm 0.185$ & $+0.991 \pm 1.128$ & - & - \\
\hline $\operatorname{AFC}(\mathrm{m})$ & $+0.199 \pm 0.014^{* *}$ & $+0.016 \pm 0.081$ & - & - \\
\hline PL (m) & $-0.079 \pm 0.148$ & $-0.701 \pm 0.744$ & - & - \\
\hline NC7 $(n)$ & $-0.0038 \pm 0.0030$ & $-0.00011 \pm 0.00016$ & - & - \\
\hline $\operatorname{NCT}(n)$ & $-0.028 \pm 0.015^{\dagger}$ & $-0.056 \pm 0.081$ & - & - \\
\hline BW (kg) & $-0.039 \pm 0.012^{* *}$ & $0.096 \pm 0.073$ & $-0.019 \pm 0.013$ & $-0.008 \pm 0.080$ \\
\hline W3M (kg) & $-0.289 \pm 0.112^{* *}$ & $-0.316 \pm 0.794$ & $-0.385 \pm 0.157^{*}$ & $-0.150 \pm 0.106$ \\
\hline W7M (kg) & $-0.092 \pm 0.107$ & $-0.899 \pm 0.719$ & $-0.277 \pm 0.123^{*}$ & $-0.595 \pm 0.797$ \\
\hline W12M (kg) & $-0.432 \pm 0.280$ & $-0.109 \pm 0.195$ & $-0.341 \pm 0.381$ & $-0.783 \pm 2.635$ \\
\hline MW (kg) & $-1.67 \pm 0.43^{* *}$ & $+5.08 \pm 2.61^{\dagger}$ & & \\
\hline $\operatorname{ADG}\left(\mathrm{g} \cdot \mathrm{d}^{-1}\right)$ & $-0.85 \pm 1.18$ & $1.12 \pm 1.03$ & - & - \\
\hline FGR $\left(\mathrm{kg} \cdot \mathrm{kg}^{-1}\right)$ & $+0.0011 \pm 0.0099$ & $0.0349 \pm 0.0565$ & - & - \\
\hline $\operatorname{RGR}\left(\% \cdot \mathrm{d}^{-1}\right)$ & $-0.000077 \pm 0.000038^{*}$ & $0.00009 \pm 0.00219$ & - & - \\
\hline $\mathrm{EX}(\%)$ & $-0.0074 \pm 0.0022^{* *}$ & $-0.0660 \pm 0.1407$ & - & - \\
\hline RY (\%) & $-0.0065 \pm 0.0061$ & $-0.0011 \pm 0.0039$ & - & - \\
\hline
\end{tabular}

${ }^{a}$ Level of significance of regression coefficients: ${ }^{*} P<0.05 ;{ }^{* *} P<0.01 ;{ }^{\dagger} P<0.10$.

${ }^{\mathrm{b}}$ See Table I for definition of trait abbreviations. 


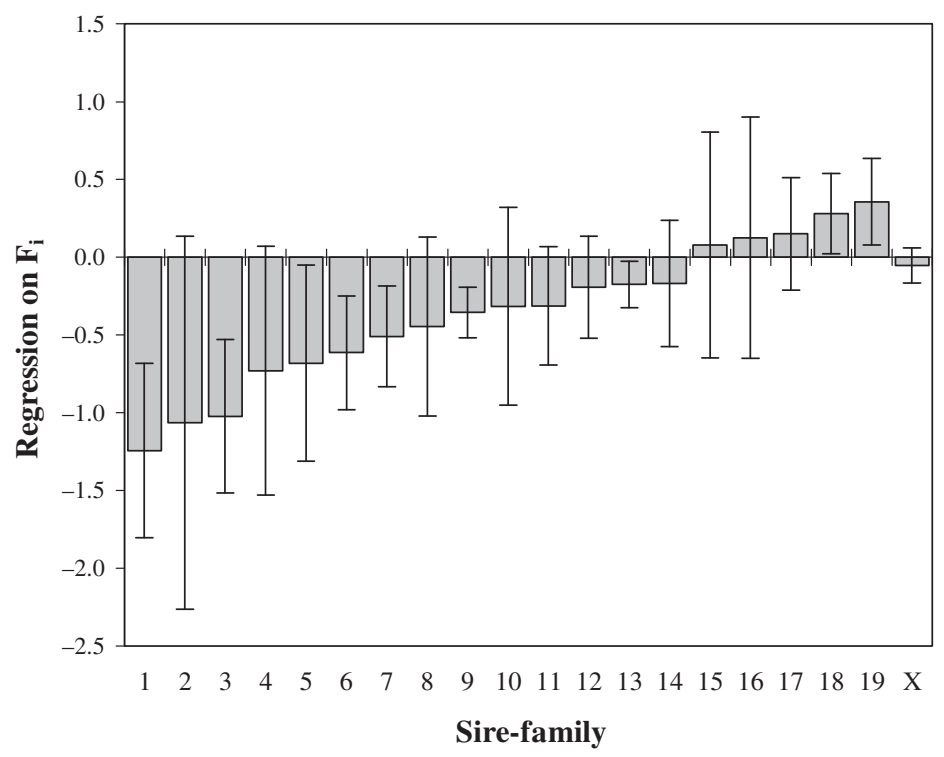

Figure 2. Estimated regression coefficients $\pm \mathrm{SE}$ of $\mathrm{W} 7 \mathrm{M}$ on individual inbreeding generated by different sires, for the most influential sire-families ( $\mathrm{X}=$ "phantom" ancestor).

impact of individual inbreeding on growth rate on the test was negligible (less than $1 \mathrm{~g} \cdot \mathrm{d}^{-1}$ per $1 \% \mathrm{~F}_{\mathrm{i}}$ ).

When expressed as a percentage of the trait means (Tab. III), all regression coefficients had an effect lower than $0.5 \%$ of the mean per $1 \%$ inbreeding, both for $F_{i}$ and for $F_{m}$. The traits with the highest percentage impact of individual inbreeding were NCT and $\mathrm{W} 3 \mathrm{M}$, followed by PL and NC7, while the highest effect of $\mathrm{F}_{\mathrm{m}}$ was observed in W3M. Inbreeding depression on carcass traits, expressed as a percentage of the mean, was extremely small (about $0.01 \%$ ). When expressed as a percentage of the phenotypic standard deviation, inbreeding depression was below $1 \%$ for most traits, with the exception of the effects of $\mathrm{F}_{\mathrm{i}}$ on $\mathrm{W} 3 \mathrm{M}$ and $\mathrm{MW}$, which were -1.56 and $-1.10 \%$, respectively.

The linear and quadratic regression coefficients of the different traits analyzed on individual and maternal inbreeding are presented in Table IV. None of the quadratic regression coefficients were statistically $(P>0.05)$ different from zero. Even though the sign of the quadratic coefficients indicates that a stronger negative impact may be occurring at higher levels of inbreeding for the majority of the traits, there was no solid evidence of a quadratic effect of inbreeding on any one of the 15 traits considered in the analyses.

The results of the analysis of W7M assuming different regression coefficients on $F_{i}$ and $F_{m}$ by sire-ancestor families are graphically presented in Figures 2 


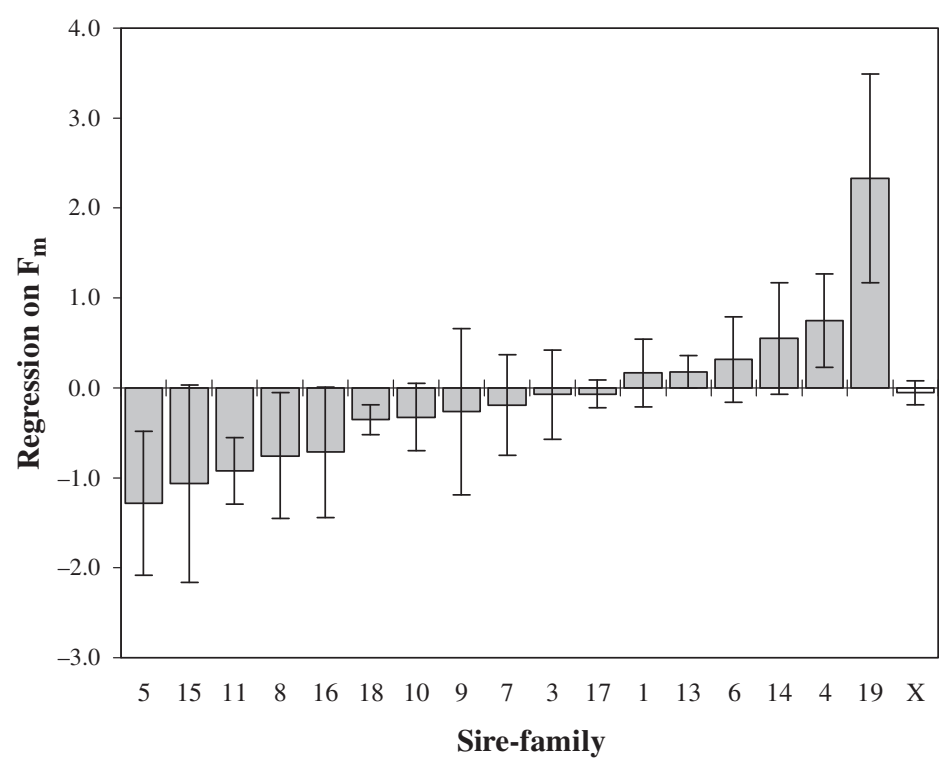

Figure 3. Estimated regression coefficients $\pm \mathrm{SE}$ of $\mathrm{W} 7 \mathrm{M}$ on maternal inbreeding generated by different sires, for the most influential sire-families $(\mathrm{X}=$ "phantom" ancestor).

and 3, respectively. The number of inbred offspring in a given sire-family ranged from 31 to 1381 in the analysis of regression on $F_{i}$ and from 34 to 1451 when regression was on $\mathrm{F}_{\mathrm{m}}$. Overall, the majority of the sires had a negative impact on the performance of their inbred offspring, but a few sires had a positive effect, especially for inbred dams of calves. Even though the standard errors of individual regression coefficients were large, there were large differences among sire-families in the impact of inbreeding on $\mathrm{W} 7 \mathrm{M}$, with linear regression coefficients by sire ranging from -1.243 to $0.357 \mathrm{~kg} / 1 \% \mathrm{~F}_{\mathrm{i}}$ and from -1.283 to $2.329 \mathrm{~kg} / 1 \% \mathrm{~F}_{\mathrm{m}}$.

No significant associations were observed between a sire contribution to individual and maternal inbreeding depression $(r=-0.27, P>0.10)$, between individual inbreeding depression and the predicted breeding value of the sire for direct genetic effects $(r=0.13, P>0.10)$ or between maternal inbreeding depression and the predicted breeding value of the sire for maternal genetic effects $(r=0.37, P>0.10)$.

\section{DISCUSSION}

The results obtained in this study clearly indicate an unfavorable effect of inbreeding on most of the beef cattle traits analyzed. For illustration purposes, 
we can consider the expected results for year 2003, where the mean inbreeding of calves was $8.5 \%$ and the expected inbreeding of cows was $6.4 \%$ (calculated from the inbreeding of calves born minus the rate of inbreeding per generation, which was $2.1 \%$ ). Comparing the expected performances of cows calving in 2003 with those that would be obtained in non-inbred animals, the mean CI is expected to increase by 1.7 days and AFC by 4.2 days, while MW is expected to decrease by $6.2 \mathrm{~kg}$, longevity by 39 days and number of calves produced through life by 0.12 . Accounting for the unfavorable impact of individual and maternal inbreeding, weights of calves born in 2003 are expected to be lower than in non-inbred calves by $0.4 \mathrm{~kg}$ at birth, and by $4.1,3.0$ and $4.3 \mathrm{~kg}$ at the ages of 3, 7 and 12 months, respectively.

When the effect of inbreeding was assessed as a percentage of the mean, it was more pronounced for NCT, W3M and PL, intermediate for other reproductive traits and weights of calves, and not significant for FGR, RGR and carcass composition. These results strongly support the view that life-history [9] or fitness-related $[11,20]$ traits are the ones where inbreeding depression has a larger effect.

The effects of inbreeding on BW estimated in our work $\left(-0.027 \mathrm{~kg} / 1 \% \mathrm{~F}_{\mathrm{i}}\right.$ and $-0.020 \mathrm{~kg} / 1 \% \mathrm{~F}_{\mathrm{m}}$ ) are of smaller magnitude than those reported in the review of Burrow [2] for the same trait $\left(-0.06 \mathrm{~kg} / 1 \% \mathrm{~F}_{\mathrm{i}}\right.$ and $\left.+0.02 \mathrm{~kg} / 1 \% \mathrm{~F}_{\mathrm{m}}\right)$. Also, the estimated impact of inbreeding on $\mathrm{W} 7 \mathrm{M}$ in our work (regression coefficients of $-0.189 \mathrm{~kg} / 1 \% \mathrm{~F}_{\mathrm{i}}$ and $-0.214 \mathrm{~kg} / 1 \% \mathrm{~F}_{\mathrm{m}}$ ) is lower than the mean values reported by Burrow [2] for weaning weight of calves $\left(-0.44 \mathrm{~kg} / 1 \% \mathrm{~F}_{\mathrm{i}}\right.$ and $\left.-0.30 \mathrm{~kg} / 1 \% \mathrm{~F}_{\mathrm{m}}\right)$. On the contrary, our estimate for inbreeding depression on MW of nearly $1 \mathrm{~kg} / 1 \% \mathrm{~F}_{\mathrm{i}}$ is lower than the mean value of $-1.30 \mathrm{~kg} / 1 \% \mathrm{~F}_{\mathrm{i}}$ in the review of Burrow [2]. It should be pointed out, however, that the results presented by Burrow [2] are mostly based on fastly and highly inbred lines of cattle, while our data originated from commercial herds subject to mild artificial selection and with moderate rates of inbreeding, thus with a lower expected effect of inbreeding depression.

The effect of inbreeding on CI in Alentejana was moderate $(+0.263 \mathrm{~d} / 1 \% \mathrm{~F})$, but was in agreement with results obtained in dairy cattle, where estimated regression coefficients of $\mathrm{CI}$ on inbreeding range from +0.26 to $+0.7 \mathrm{~d}$ $[22,29]$. Our estimate for the reduction in longevity with increased inbreeding was in line with, but lower than, the findings of different studies in Jersey [3] and Holstein [22,28,29,33] dairy cows.

In general, our estimates of the linear effect of inbreeding depression for different traits are in the lower range of values reported in the literature. This could be due to differences among populations, or possibly to the fact that the results summarized in the review of Burrow [2] are mostly based on rapidly inbred 
lines, where the effects of inbreeding depression are expected to be more dramatic, because natural selection is not as effective in counteracting inbreeding under these circumstances [10]. For reproductive traits, the comparisons with results in dairy cattle also indicate a milder effect of inbreeding in Alentejana than in dairy cows. Our data were obtained in herds kept extensively, under feed and climate conditions which are often constraining, and it was therefore anticipated that they would show a more tangible effect of inbreeding, given that the level of inbreeding depression has been shown to be higher when inbreeding effects are expressed in harsh environmental conditions [18]. This was not the case, and it can be argued that the intense management to which dairy cows are subject is more challenging than conditions found in extensive production, and thus inbreeding has a more harmful effect in highly intensified systems. It is also possible that a lower impact of inbreeding is detected in Alentejana, because it has experienced a bottleneck in the recent past and would then be less affected by further inbreeding [7].

No evidence was found of non-linear associations between inbreeding and any of the 15 beef cattle traits analyzed. This result suggests that epistasis involving dominance effects may be minor for these traits, but it is possible that the limited range of inbreeding coefficients analyzed, with a paucity of results for animals with $F_{i}>0.25$, could cause difficulties in detecting a non-linear effect of inbreeding [18].

The analysis of within-family inbreeding depression on W7M indicates that there is wide variation among sires in the impact that they have as contributors to either individual or maternal inbreeding depression. Differences among the sires with extreme regression coefficients were 1.6 and $3.6 \mathrm{~kg}$ for individual and maternal inbreeding depression, respectively. Even though the majority of the sires had a detrimental effect on W7M through the inbreeding which they generate, some sires had a positive effect, either on individual or maternal inbreeding effects, on W7M. The positive inbreeding "depression" could be just due to sampling error or result from the existence of alleles with negative dominance deviations.

The heterogeneity among sire-families in the effects of inbreeding would suggest that there are large differences in genetic load among ancestors, both for individual as well as for maternal inbreeding effects. Moreover, no association was found among sire effects on individual and maternal inbreeding depression, or between these and estimated breeding values for genetic direct and maternal effects.

Our results confirm the findings of Lacy et al. [19] in mice, Rodrigañez et al. [27] in swine and Miglior et al. [25] and Gulisija et al. [15] in dairy cattle, who have also reported differences among founder families in inbreeding depression. 
The magnitude of the family differences found in our study suggests that the genetic load may be essentially affected by a few alleles with major effects [19].

Reproductive technologies currently available allow high selection intensity in most livestock species and are combined with selection methods which take into account family information, such as best linear unbiased prediction. As a result, response to selection has been enhanced, but rates of inbreeding have also increased and they currently represent a serious concern for several breeding programs, due to the possible consequences in terms of inbreeding depression and genetic variability $[17,31,36]$. Therefore, methods have been proposed where selection is carried out by appropriately weighing the predicted breeding value of an individual and the inbreeding generated in the population $[14,23,30,35]$. The large differences found in our study between sire-families in their genetic load indicate that it might be interesting to take this factor into account in breeding decisions, as a scaling factor to be used in addition to the inbreeding generated in the population.

\section{ACKNOWLEDGEMENTS}

The authors thank the "Associação dos Criadores de Bovinos da Raça Alentejana" for providing data used in this study and Estação Zootécnica Nacional for financial support.

\section{REFERENCES}

[1] Boldman K.G., Kriese L.A., van Vleck L.D., van Tassell C.P., Kachman S.D., A manual for use of MTDFREML. A set of programs to obtain estimates of variances and covariances [Draft], USDA-ARS, Lincoln, NE, 1995.

[2] Burrow H.M., The effects of inbreeding in beef cattle, Anim. Breed. Abstr. 61 (1993) 737-751.

[3] Caraviello D.Z., Weigel K.A., Gianola D., Analysis of the relationship between type traits, inbreeding, and functional survival in Jersey cattle using a Weibull proportional hazards model, J. Dairy Sci. 86 (2003) 2984-2989.

[4] Carolino N., Gama L.T., Indicators of genetic erosion in an endangered population: the Alentejana cattle breed in Portugal, J. Anim. Sci. 86 (2008) $47-56$.

[5] Carolino N., Espadinha P., Gama L.T., Estimates of genetic parameters for reproductive, growth and carcass traits in the Alentejana breed of cattle, in: Proceedings of the 8th World Congress on Genetics Applied to Livestock Production, 13-18 August 2006, Belo Horizonte, MG, Brazil, CD-ROM communication no. 03-33. 
[6] Charlesworth B., Charlesworth D., The genetic basis of inbreeding depression, Genet. Res. 74 (1999) 329-340.

[7] Charlesworth D., Charlesworth B., Inbreeding depression and its evolutionary consequences, Annu. Rev. Ecol. Syst. 18 (1987) 237-268.

[8] Croquet C., Mayeres P., Gillon A., Hammami H., Vanderick S., Gengler N., Linear and curvilinear effects of inbreeding on production traits for Walloon Holstein cows, J. Dairy Sci. 90 (2007) 465-471.

[9] DeRose M.A., Roff D.A., A comparison of inbreeding depression in life-history and morphological traits in animals, Evolution 53 (1999) 1288-1292.

[10] Falconer D.S., Replicated selection for body weight in mice, Genet. Res. 22 (1973) 291-321.

[11] Falconer D.S., Mackay T.F.C., Introduction to quantitative genetics, 4th edn., Longman Group Ltd., Essex, England, 1996.

[12] FAO, Secondary Guidelines for Development of National Farm Animal Genetic Resources Management Plans, FAO, Rome, Italy, 1988.

[13] Fitzhugh H.A., Taylor S.C.S., Genetic analysis of degree of maturity, J. Anim. Sci. 33 (1971) 717-725.

[14] Grundy B., Villanueva B., Woolliams J.A., Dynamic selection for maximizing response with constrained inbreeding in schemes with overlapping generations, Anim. Sci. 70 (2000) 373-382.

[15] Gulisija D., Gianola D., Weigel K.A., Toro M.A., Between-founder heterogeneity in inbreeding depression for production in Jersey cows, Livestock Sci. 104 (2006) 244-253.

[16] Gulisija D., Gianola D., Weigel K.A., Nonparametric analysis of the impact of inbreeding on production in Jersey cows, J. Dairy Sci. 90 (2007) 493-500.

[17] Kearney J.F., Wall E., Villanueva B., Coffey M.P., Inbreeding trends and application of optimized selection in the UK Holstein population, J. Dairy Sci. 87 (2004) 3503-3509.

[18] Kristensen T.N., Sørensen A.C., Inbreeding - lessons from animal breeding, evolutionary biology and conservation genetics, Anim. Sci. 80 (2005) 121-133.

[19] Lacy R.C., Alaks G., Walsh A., Hierarchical analysis of inbreeding depression in Peromyscus polionotus, Evolution 50 (1996) 2187-2200.

[20] Lynch M., Walsh B., Genetics and analysis of quantitative traits, 1st edn., Sinauer Associates, Sunderland, 1998.

[21] Mateus J.C., Penedo M.C.T., Alves V.C., Ramos M., Rangel-Figueiredo M.T., Genetic diversity and differentiation in Portuguese cattle breeds using microsatellites, Anim. Genet. 35 (2004) 106-113.

[22] McParland S.M., Kearney J.F., Rath M., Berry D.P., Inbreeding effects on milk production, calving performance, fertility, and conformation in Irish HolsteinFriesians, J. Dairy Sci. 90 (2007) 4411-4419.

[23] Meuwissen T.H.E., Maximizing the response of selection with a predefined rate of inbreeding, J. Anim. Sci. 75 (1997) 934-940.

[24] Meuwissen T.H.E., Woolliams J.A., Effective sizes of livestock populations to prevent a decline in fitness, Theor. Appl. Genet. 89 (1994) 1019-1026. 
[25] Miglior F.A., Burnside E.B., Hokenboken W.D., Heterogeneity among families of Holstein cattle in inbreeding depression for production traits, in: Proceedings of the 5th World Congress on Genetics Applied to Livestock Production, 7-12 August 1994, Vol. 28, Guelph, Ontario, Canada, pp. 479-482.

[26] Pederson K.S., Kristensen T.N., Loeschcke V., Effects of inbreeding and rate of inbreeding in Drosophila melanogaster - Hsp70 expression and fitness, J. Evol. Biol. 18 (2005) 756-762.

[27] Rodrigañez J., Toro M.A., Rodríguez M.C., Silio L., Effect of founder allele survival and inbreeding depression on litter size in a closed line of Large White pigs, Anim. Sci. 67 (1998) 573-582.

[28] Sewalem A., Kistemaker G.J., Miglior F., van Doormaal B.J., Analysis of inbreeding and its relationship with functional longevity in Canadian dairy cattle, J. Dairy Sci. 89 (2006) 2210-2216.

[29] Smith L.A., Cassell B.G., Pearson R.E., The effects of inbreeding on the lifetime performance of dairy cattle, J. Dairy Sci. 81 (1998) 2729-2737.

[30] Sonesson A.K., Grundy B., Woolliams J.A., Meuwissen T.H.E., Selection with control of inbreeding in populations with overlapping generations: a comparison of methods, Anim. Sci. 70 (2000) 1-8.

[31] Sørensen A.C., Sorensen M.K., Berg P., Inbreeding in Danish dairy cattle breeds, J. Dairy Sci. 88 (2005) 1865-1872.

[32] Sørensen C., Madsen P., Sørensen M.K., Berg P., Udder health shows inbreeding depression in Danish Holsteins, J. Dairy Sci. 89 (2006) 4077-4082.

[33] Thompson J.R., Everett R.W., Hammerschmidt N.L., Effects of inbreeding on production and survival in Holsteins, J. Dairy Sci. 83 (2000) 1856-1863.

[34] van Vleck L.D., Selection index and introduction to mixed model methods, CRC Press, Boca Raton, USA, 1993.

[35] Villanueva B., Pong-Wong R., Woolliams J.A., Avendaño S., Managing genetic resources in selected and conserved populations, in: Villanueva B., Sinclair K.D., Townsend S. (Eds.), Farm Animal Genetic Resources, Nottingham University Press, Nottingham, England, 2004, pp. 113-131.

[36] Weigel K.A., Controlling inbreeding in modern breeding programs, J. Dairy Sci. 84 (E. Suppl.) (2001) E177-E184.

[37] Willham R.L., The role of maternal effects in animal breeding: III - Biometrical aspects of maternal effects in animals, J. Anim. Sci. 35 (1972) 1288-1293. 